\title{
Pre-burn malnutrition increases operative mortality in burn patients who undergo early excision and grafting in a sub-Saharan African burn unit
}

\author{
Joana Grudziak ${ }^{a, c}$, Carolyn Snock ${ }^{b}$, Tiyamike Zalinga ${ }^{c}$, Wone Banda ${ }^{c}$, \\ Jared Gallaher ${ }^{a, c}$, Laura Purcell ${ }^{a}$, Bruce Cairns ${ }^{a}$, Anthony Charles ${ }^{a, c, *}$ \\ ${ }^{a}$ Department of Surgery, University of North Carolina at Chapel Hill, United States \\ ${ }^{\mathrm{b}}$ Department of Nutrition and Dietetics, University of North Carolina Hospitals, United States \\ ${ }^{\mathrm{c}}$ Kamuzu Central Hospital, Lilongwe, Malawi
}

A R T I C L E I N F O

Article history:

Received 31 May 2017

Received in revised form

12 September 2017

Accepted 4 October 2017

Keywords:

Burn mortality

Post-operative burn mortality

Burn nutrition

Malnutrition

Sub-Saharan Africa

\section{A B S T R A C T}

Introduction: In the developed world, pre-existing malnutrition in the burn population influences operative outcomes. However, studies on pre-existing malnutrition and operative outcomes of burn patients in the developing world are lacking. We therefore sought to characterize the burn injury outcomes following operative intervention based on nutritional status.

Methods: This is a retrospective review of operative patients admitted to our burn unit from July 2011 to May 2016. Age-adjusted Z scores were calculated for height, weight, weight for height, and mid-upper arm circumference (MUAC). Following bivariate analysis, we constructed a fully adjusted logistic regression model of significant predictors of postoperative mortality, both overall and for specific age categories.

Results: Of the 1356 admitted patients, 393 received operative intervention (29\%). Of those, 205 $(52.2 \%)$ were male, and the median age was 6 years $(3,25)$, with 265 patients $(67 \%)$ aged $\leq 16$ years. The median TBSA was $15.4 \%(10 \%-25 \%)$ and open flames caused the majority of burns (64\%), though in children under 5 , scalds were the predominant cause of burn (52.2\%). Overall mortality was $14.5 \%$ (57 patients) and ranged from $9.09 \%$ for patients aged 6-16, to $33.3 \%$ for adults $\geq 50$ years. Increased time from injury to operative intervention was protective (OR: $0.90,95 \%$ CI: $0.83,0.99)$. In post-operative patients with z-scores, increasing \%TBSA burned (OR: 1.11, 95\% CI: 1.05, 1.17) and increasing malnutrition (OR: 1.46, 95\% CI: 1.03, 1.91) predicted death in the adjusted model.

Conclusion: Poor nutrition is an important risk factor for post-operative mortality in burned patients in resource-poor settings. Screening for malnutrition and designing effective interventions to optimize nutritional status may improve surgical outcomes in LMIC burn patients.

\footnotetext{
* Corresponding author at: UNC School of Medicine, University of North Carolina, 4008 Burnett Womack Building, CB 7228, Chapel Hill, NC 27599-7228, United States.

E-mail address: anthchar@med.unc.edu (A. Charles).

https://doi.org/10.1016/j.burns.2017.10.003
} 


\section{Introduction}

Burn patients in low- and middle-income countries (LMICs) suffer a disproportional burden of global burn mortality, with over $90 \%$ of burn deaths [1]. In sub-Saharan Africa (SSA), burn mortality affects mainly children. The region accounts for $64 \%$ of the world's burn mortality in the 0-4year old group, and $78 \%$ of burn mortality in the 5-14year age group [1-5]. In highincome country burn centers, interventions that improve burn injury outcomes include: adequate fluid resuscitation, early excision and grafting, early enteral nutrition, and admission to a burn unit [6,7]. We have previously shown that in a resourcepoor setting there is an increased mortality associated with early excision and grafting [6]. However, the causal relationship between early excision and grafting and increased mortality could not be clearly delineated.

Despite the low incidence of preexisting malnutrition in high-income countries (HICs), the hypermetabolic effect of burn injury on nutritional status is well characterized [7-15] and early enteral nutrition plays a vital role in burn management. Despite adequate baseline nutritional status and optimal nutritional supplementation, patients with severe burns can lose up to $25 \%$ of their lean body mass after an acute burn injury $[10,12]$. This effect is especially pronounced in children because of their lower metabolic reserve and increased caloric and protein estimates in relation to body size $[13,14]$. The prevalence of pre-existing malnutrition in children living in SSA is high, yet there is a paucity of data regarding the effect of pre-existing malnutrition on postoperative mortality [16-18].

The World Health Organization (WHO) uses three indicators to denote poor nutritional status: malnutrition, wasting and stunting. It defines moderate pediatric malnutrition as a weight-for-age between -2 and $-3 \mathrm{z}$-scores below the median of the WHO growth standards. Moderate wasting and stunting are described as weight-for-height and height-for-age falling between -2 and -3 z-scores [19]. The Academy of Nutrition and Dietetics (AND) and the American Society for Parenteral and Enteral Nutrition (ASPEN) use the same pediatric parameters, but include also a mid-upper-arm-circumference (MUAC)-for-age $z$-score $[20,21]$. Weight-for-age changes are thought to represent acute changes to nutritional status or overall health, whereas decreased height-for-age (stunting) tends to represent exposure to a chronic state of either malnutrition or disease [19].

Adult nutritional status indicators are less well accepted. ASPEN recommends 2 or more of the following for documentation of adult malnutrition: energy intake $<75 \%$ of ideal, weight loss, loss of muscle mass, loss of subcutaneous fat, localized edema, and diminished hand grip strength. These indicators are based on expert opinion and recommended for the United States population; no such consensus exists for adults in resource-poor settings. The WHO uses Body Mass Index (BMI) in women of childbearing age as an indicator of malnutrition, and both the Centers for Disease Control (CDC) and the WHO define a $\mathrm{BMI}<18.5 \mathrm{~kg} / \mathrm{m}^{2}$ as underweight [22].

Malawi, a landlocked country in southeastern Africa, has a 2016 population of over 17 million people, and a life expectancy of 57 and 60 years for males and females, respectively. In 2011,
$50 \%$ of the population lived below the poverty line [23]. In 2016, the per capita gross domestic product (GDP) was US $\$ 300$, representing a $41 \%$ decline from a high of US $\$ 512$ in 2011 [24]. In 2014, $20.7 \%$ of the population could not achieve the minimum dietary energy consumption [23]. Healthcare in Malawi is free and universal with a per capita healthcare spending of US $\$ 29$ [25].

The prevalence of underweight in children 0-5 years living in Malawi increased from 12.1 to $16.7 \%$ between 2009 and 2014. In $2010,48 \%$ of children $\leq 5$ years were stunted. In 2004-2005, the most recent data available, $9.2 \%$ of women of childbearing age had a BMI under $18.5 \mathrm{~kg} / \mathrm{m}^{2}$ [23]. Given the high prevalence of burn and under nutrition, we hypothesize that the presence of pre-existing nutritional stress in burn patients who undergo operative intervention in our SSA burn unit is associated with increased mortality.

\section{Methods}

We performed a retrospective review of prospective data entered into the Kamuzu Central Hospital (KCH) burn unit database. $\mathrm{KCH}$, located in Malawi's capital of Lilongwe, is a public, 600-bed, tertiary care hospital with a catchment population of approximately 6 million people. All patients receive treatment free of charge. The $\mathrm{KCH}$ burn unit was commissioned in 2011 in partnership with the North Carolina Jaycee Burn Center. It has 31 beds, 8 nurses, 2 nursing assistants, and 1-2 clinical officers who oversee clinical management and perform surgeries with attending surgeon oversight [5]. Burn patients receive the standard hospital meal allotment of three servings of corn-meal porridge or cake served with peanut butter for breakfast, a vegetable or protein stew for lunch and again with peanut butter for dinner. They also receive two boiled eggs per day from the burn unit funds. Enteral feeding is almost always achieved per os and nasogastric tubes are occasionally utilized. The amount of nutrition delivered to each patient does not vary with burn severity. Children who are breast fed prior to burn injury continue breast milk during their admission. There is no dedicated nutritionist or separate nutritional support,

All patients admitted to the burn unit between 1 July 2011 and 1 May 2016, who received operative intervention were included in this study. Operative intervention consisted mainly of debridement, burn wound excision, escharotomies and skin grafting. The primary aim was to determine the relationship between pre-existing malnutrition, defined using any of the WHO and/or AND/ASPEN indicators or BMI for adults, and post-operative mortality. The primary outcome was in-hospital mortality among patients undergoing surgery in the burn unit during the period under study. We analyzed mortality for all patients, as well as for a priori determined age categories of $0-5,6-16,17-49$, and $\geq 50$ years.

We first compared the demographic and clinical characteristics of operative and non-operative patients. Non-operative patients were then excluded from the remainder of the study. Bivariate analysis of each independent variable was performed based on mortality, using Pearson's correlation, two tailed Fisher's exact test, 2-sample T-test, or Kruskal-Wallis testing, as appropriate. Means are presented with standard 
Table 1 - xxx.

\begin{tabular}{|c|c|c|c|c|c|}
\hline Variable & & $\begin{array}{l}\text { Entire cohort } \\
\quad(1353)\end{array}$ & $\begin{array}{c}\text { Operative } \\
\text { patients (393) }\end{array}$ & $\begin{array}{l}\text { Non operative patients } \\
(963)\end{array}$ & $\begin{array}{c}\mathrm{p} \\
\text { Value }\end{array}$ \\
\hline \multicolumn{6}{|l|}{ Baseline characteristics } \\
\hline \multirow[t]{3}{*}{ Sex } & & & & & 0.122 \\
\hline & Male & $750(55.4 \%)$ & $205(52.2 \%)$ & $545(56.8 \%)$ & \\
\hline & Female & $603(44.57 \%)$ & $188(47.8 \%)$ & $415(43.2 \%)$ & \\
\hline \multirow{6}{*}{$\begin{array}{l}\text { Age (years) } \\
\text { Age, categories }\end{array}$} & Median (Range) & $3(2,12)$ & $6(3,25)$ & $3(1,8)$ & $<0.001$ \\
\hline & & & & & $<0.001$ \\
\hline & $<5$ & $838(62.1 \%)$ & $186(47.7 \%)$ & $652(68 \%)$ & \\
\hline & $6-16$ & $217(16.1 \%)$ & $79(20.3 \%)$ & $138(14.4 \%)$ & \\
\hline & $17-49$ & $242(17.9 \%)$ & $107(27.4 \%)$ & 135 (14.1\%) & \\
\hline & $50+$ & $52(3.85 \%)$ & $18(4.62 \%)$ & $34(3.55 \%)$ & \\
\hline \multirow[t]{5}{*}{ Comorbidities } & & & & & $<0.001$ \\
\hline & None & $1120(84.6 \%)$ & $278(72.8 \%)$ & $842(89.4 \%)$ & \\
\hline & Epilepsy & $165(12.5 \%)$ & $92(24.1 \%)$ & $73(7.75 \%)$ & \\
\hline & Pre-existing malnutrition & $23(1.74 \%)$ & $7(1.83 \%)$ & $16(1.70 \%)$ & \\
\hline & Other & $16(1.21 \%)$ & $5(1.31 \%)$ & $11(1.17 \%)$ & \\
\hline \multirow[t]{4}{*}{ HIV status } & & & & & 0.001 \\
\hline & Nonreactive & $208(15.9 \%)$ & $81(21.3 \%)$ & $127(13.6 \%)$ & \\
\hline & Reactive & $7(0.53 \%)$ & $3(0.79 \%)$ & $4(0.43 \%)$ & \\
\hline & Unknown & $1,096(83.6 \%)$ & $296(77.9 \%)$ & $800(85.9 \%)$ & \\
\hline \multirow[t]{7}{*}{ Admission year } & & & 393 & 963 & $<0.001$ \\
\hline & 2011 & $164(12.1 \%)$ & $62(15.8 \%)$ & $102(10.6 \%)$ & \\
\hline & 2012 & $278(20.5 \%)$ & $105(26.7 \%)$ & $173(18 \%)$ & \\
\hline & 2013 & $252(18.6 \%)$ & $57(14.5 \%)$ & $195(20.3 \%)$ & \\
\hline & 2014 & $281(20.7 \%)$ & $67(17.1 \%)$ & $214(22.2 \%)$ & \\
\hline & 2015 & $282(20.8 \%)$ & $79(20.1 \%)$ & $203(21.1 \%)$ & \\
\hline & 2016 & $99(7.30 \%)$ & $23(5.85 \%)$ & $76(7.89 \%)$ & \\
\hline \multicolumn{6}{|c|}{ Burn injury characteristics } \\
\hline \multirow[t]{2}{*}{ TBSA burned (\%) } & & & & & 0.04 \\
\hline & Median (Range) & $15(8.5,24)$ & $15.4(10,25)$ & $14(8,23)$ & \\
\hline \multirow{4}{*}{$\begin{array}{l}\text { Time to presentation } \\
\text { (hours) }\end{array}$} & & & & & $<0.001$ \\
\hline & $<24 \mathrm{~h}$ & $845(64.5 \%)$ & $176(46.2 \%)$ & $669(72.1 \%)$ & \\
\hline & $24-48 \mathrm{~h}$ & $73(5.57 \%)$ & $21(5.51 \%)$ & $52(5.60 \%)$ & \\
\hline & $>48 \mathrm{~h}$ & $392(29.9 \%)$ & $184(48.3 \%)$ & $208(22.4 \%)$ & \\
\hline \multirow[t]{2}{*}{ Days to presentation } & & & & & 0.002 \\
\hline & Median (Range) & $6(4,14)$ & $7(4,18)$ & $6(3,10)$ & \\
\hline \multirow[t]{5}{*}{ Mechanism } & & & & & $<0.001$ \\
\hline & Scald & $805(59.8 \%)$ & $133(34.3 \%)$ & $672(70.2 \%)$ & \\
\hline & Flame & $517(38.4 \%)$ & $247(64.7 \%)$ & $270(28.2 \%)$ & \\
\hline & Contact & $8(0.59 \%)$ & $3(0.77 \%)$ & $5(0.52 \%)$ & \\
\hline & Electrical & $16(1.19 \%)$ & $5(1.29 \%)$ & $11(1.15 \%)$ & \\
\hline \multicolumn{6}{|l|}{ Nutritional characteristics } \\
\hline \multirow[t]{3}{*}{ Patient weighed } & & 1356 & 393 & 963 & 0.006 \\
\hline & Yes & $697(51.4 \%)$ & $225(57.3 \%)$ & $472(49 \%)$ & \\
\hline & No & $659(51.4 \mathrm{a} 50$ & $168(43.8 \%)$ & $491(51 \%)$ & \\
\hline \multicolumn{6}{|l|}{ Time to weight (days) } \\
\hline & Median (range) & $3(0,7)$ & $5(0,10)$ & $2(0,6)$ & 0.001 \\
\hline Weight-for-age $\mathrm{z}$ score & & 541 & 142 & 399 & 0.116 \\
\hline & Median (Range) & $-0.83(-1.72,0.19)$ & $-0.97(-1.8,-0.18)$ & $-0.74(-1.7,0.31)$ & \\
\hline Height-for-age z score & & 317 & 79 & 238 & 0.195 \\
\hline & Median (Range) & $-2.35(-3.57,-1.22)$ & $-2.35(-4.16,-1.25)$ & $-2.33(-3.43,-1.19)$ & \\
\hline Weight-for-height z score & & 212 & 42 & 170 & 0.495 \\
\hline & Median (Range) & $0.825(-0.35,1.93)$ & $0.855(-1.13,1.66)$ & $0.825(-0.18,1.99)$ & \\
\hline MUAC z score & & 299 & 58 & 242 & 0.06 \\
\hline & Median (Range) & $-0.17(-0.93,0.68)$ & $-0.58(-1.27,0.64)$ & $-0.1(-0.76,0.69)$ & \\
\hline Combined $\mathrm{Z}$ score & & 600 & 160 & 443 & 0.379 \\
\hline & Median (Range) & $-1.64(-2.79,-0.46)$ & $-1.63(-3.13,-0.58)$ & $-1.64(-2.75,-0.43)$ & \\
\hline BMI $\left(\mathrm{kg} / \mathrm{m}^{2}\right)$ & & 131 & 49 & 81 & 0.805 \\
\hline & Median (Range) & $21(17.1,24.2)$ & $20.3(18.4,23.7)$ & $21.1(16.9,24.5)$ & \\
\hline Interventions & & & & & \\
\hline Traditional medicine & & & & & 0.682 \\
\hline & Yes & $180(14.3 \%)$ & 56 (14.9\%) & $124(14 \%)$ & \\
\hline & No & $1081(85.7 \%)$ & $320(85.1 \%)$ & $761(86 \%)$ & \\
\hline Antibiotics on admission & & & & & $<0.001$ \\
\hline
\end{tabular}


Table 1 (continued)

\begin{tabular}{|c|c|c|c|c|c|}
\hline Variable & & $\begin{array}{c}\text { Entire cohort } \\
\quad(1353)\end{array}$ & $\begin{array}{c}\text { Operative } \\
\text { patients (393) }\end{array}$ & $\begin{array}{c}\text { Non operative patients } \\
\text { (963) }\end{array}$ & $\begin{array}{c}\mathrm{p} \\
\text { Value }\end{array}$ \\
\hline & Yes & $954(71.6 \%)$ & $305(78.6 \%)$ & $649(68.7 \%)$ & \\
\hline & No & $379(28.4 \%)$ & $83(21.4 \%)$ & $296(31.3 \%)$ & \\
\hline \multicolumn{6}{|l|}{ Outcomes } \\
\hline \multirow{2}{*}{$\begin{array}{l}\text { Length of hospital stay } \\
\text { (days) }\end{array}$} & & & 390 & 959 & $<0.001$ \\
\hline & Median (Range) & $13(7,31)$ & $39(23,65)$ & $9(5,17)$ & \\
\hline \multirow[t]{4}{*}{ Disposition } & & 1,336 & 387 & 949 & 0.128 \\
\hline & Lived & $1,025(76.7 \%)$ & $311(80.4 \%)$ & $714(75.2 \%)$ & \\
\hline & Left against medical advice & $74(5.54 \%)$ & $19(4.91 \%)$ & $55(5.8 \%)$ & \\
\hline & Died & $237(17.7 \%)$ & $57(14.7 \%)$ & $180(19 \%)$ & \\
\hline \multirow[t]{2}{*}{ Time to death (days) } & & & & & $<0.001$ \\
\hline & Median (Range) & $10(3,20)$ & $7(2,15)$ & $19(12,35)$ & \\
\hline \multirow[t]{5}{*}{ Mortality by age category } & & & & & 0.073 \\
\hline & $0-5$ & $134 / 826(16.2 \%)$ & 27/182 (14.8\%) & 107/644 (16.6\%) & 0.565 \\
\hline & $6-16$ & $32 / 213(15 \%)$ & $7 / 77(9.09 \%)$ & $25 / 136(18.4 \%)$ & 0.068 \\
\hline & $17-49$ & $50 / 239(20.9 \%)$ & $17 / 107(15.9 \%)$ & $33 / 132(25 \%)$ & 0.085 \\
\hline & $50+$ & $21 / 51(41.2 \%)$ & $6 / 18(33.3 \%)$ & $15 / 33(45.5 \%)$ & 0.401 \\
\hline
\end{tabular}

deviations and medians with interquartile ranges (IQR). Variables found to significantly affect outcome in the operative cohort in bivariate analysis were used in multivariate logistic regression to construct a fully adjusted model of significant predictors of operative mortality.

Percent of total body surface area burned (\%TBSA) is currently assessed twice: once in the casualty department, and secondly upon arrival on the burn ward. There was no statistically significant difference between these measurements, so an average of the two measurements was used when available. Where only one measurement was available, this was used in the final analysis. Patients who requested discharge before completion of treatment, or who left against medical advice $(4.9 \%$ of operative patients and $5.8 \%$ of nonoperative patients) were included in the "living" category for the purposes of the final outcome.

All statistical analysis was performed using STATA/SE 14.1 (Stata Corp LP, College Station, TX). Age-adjusted z-scores were calculated for height, weight, and weight-for-height, using the STATA zscore06 package [26], which is based on 2006 WHO data for children 0-60 months. For children and adults aged 6-20 years, we used the WHO Anthro calculator application, available from the same source. Body mass index (BMI) was calculated for adults age $>16$ by dividing their weight by height squared $\left(\mathrm{kg} / \mathrm{m}^{2}\right)$. MUAC-for-age was calculated using an online calculator, based on 2007 WHO data [27]. Z-scores lower than -6 standard deviations (SDs) of the mean for height, weight, and lower than -5 SDs for weight for height for age, and MUAC for age, were dropped from subsequent analysis, per WHO recommendations [26]. Because some patients had incomplete data available (e.g. only height or only weight), we utilized any one of the available indicators of nutritional stress as the nutritional variable for $\mathrm{z}$-score determination. When more than one indicator was available, we used the lowest value. For example, a child who had a z-score of -1.64 for weight-for-height, and a -1.84 for stunting, would be entered as $\mathrm{a}-1.84$ in the utilized nutritional stress variable.
Of the 1356 admitted patients, 393 (29\%) received operative intervention. Males represented 52.2\% (205 patients), and the median age of operative patients was 6 years (3-25). The median TBSA was $15.4 \%$ (10-25\%) and open flames caused the majority of burns (64\%), though in children under 5 years, scalds were the predominant cause of burn (52.2\%). There was no statistically significant difference in mortality in the operative and non-operative groups with 57 (14.7\%) versus $180(19 \%)$ deaths in each group, respectively.

Operative and non-operative patients groups differed in several ways (Table 1$)$. The operative group was older (median age 6 versus 3 years, $\mathrm{p}<0.001)$; included more epileptics $(24 \%$ versus $7.75 \%, \mathrm{p}<0.001)$; received antibiotics more frequently (78.6\% vs. 68.7\%); and were more likely to present greater than $48 \mathrm{~h}$ from injury ( $48.3 \%$ vs. $22.4 \%, \mathrm{p}<0.001)$. Both groups had a similar mortality, although the non-operative patients died after a longer hospital stay than the operative cohort (19 vs 7 days, $\mathrm{p}<0.001)$. Flame burns predominated in this group (64.7\% vs. $28.2 \%, p<0.001)$. Median TBSA in the operative and non-operative group was 15.4 and $14 \%$, respectively $(p=0.04)$. Nutritional status appeared similar in the two groups. The overall nutrition $z$-score was -1.63 (IQR $-3.13,-0.58$ ) and - 1.64 (IQR $-2.75,-0.43)$ in the operative and non-operative groups, respectively $(p=0.379)$. The two groups did not differ in BMI.

The remainder of analysis was performed in the operative cohort only. Variables associated with the primary outcome of mortality are shown in Table 2. Surviving operative patients had a median \%TBSA of $15 \%$ (IQR 9, 20) whereas those who died had a median \%TBSA of $30 \%$ (IQ 19, 37.5; $\mathrm{p}=0.0001$ ). In patients who survived, hospital length of stay was longer than in those who died (44 days versus 19 days, $\mathrm{p}=0.0001$ ); and surgical intervention occurred later (14 days versus 6 days, $p=0.0001$ ), with patients who died undergoing significantly more escharotomies and fewer skin grafts. Operative mortality was lowest for children aged 6-16 years $(9.09 \%)$, and highest for adults aged 50 years and over, at $33.3 \%$. 
Table 2 - Operative patients, living vs dying.

\begin{tabular}{|c|c|c|c|c|}
\hline Variable & & Lived (330) & Died (57) & $\mathrm{p}$ Value \\
\hline \multicolumn{5}{|l|}{ Baseline characteristics } \\
\hline \multirow[t]{3}{*}{ Sex } & & & & 0.073 \\
\hline & Male & $166(82.2 \%)$ & $36(17.8 \%)$ & \\
\hline & Female & $164(88.6 \%)$ & $21(11.4 \%)$ & \\
\hline \multicolumn{5}{|l|}{ Age, overall } \\
\hline & Median (range) & $6(3,22)$ & $7(3,33)$ & 0.14 \\
\hline \multirow[t]{5}{*}{ Comorbidities } & & & & 0.200 \\
\hline & None & 236 (73.5\%) & $37(67.3 \%)$ & \\
\hline & Epilepsy & $75(23.4 \%)$ & $16(29.1 \%)$ & \\
\hline & Pre-existing malnutrition & $7(2.2 \%)$ & - & \\
\hline & Other & $3(0.9 \%)$ & $2(3.6 \%)$ & \\
\hline \multirow[t]{4}{*}{ HIV status } & & & & 0.421 \\
\hline & Nonreactive & $70(22.0 \%)$ & $9(16.1 \%)$ & \\
\hline & Reactive & $2(0.63 \%)$ & $1(1.8 \%)$ & \\
\hline & Unknown & $246(77.4 \%)$ & $46(82.1 \%)$ & \\
\hline \multirow[t]{7}{*}{ Admission year } & & & & 0.210 \\
\hline & 2011 & 49 (79.0\%) & $13(21.0 \%)$ & \\
\hline & 2012 & $94(90.4 \%)$ & $10(9.6 \%)$ & \\
\hline & 2013 & 47 (85.4\%) & $8(14.6 \%)$ & \\
\hline & 2014 & $52(78.8 \%)$ & $14(21.2 \%)$ & \\
\hline & 2015 & $67(87.0 \%)$ & $10(13.0 \%)$ & \\
\hline & 2016 & $21(91.3 \%)$ & $2(8.7 \%)$ & \\
\hline \multirow[t]{2}{*}{ TBSA burned } & & & & 0.0001 \\
\hline & Median (Range) & $15(9,20)$ & $30(19,37.5)$ & \\
\hline \multirow[t]{4}{*}{ Time to presentation } & & & & 0.410 \\
\hline & $<24 \mathrm{~h}$ & $144(45.0 \%)$ & $30(54.6 \%)$ & \\
\hline & $24-48 \mathrm{~h}$ & $18(5.6 \%)$ & $3(5.4 \%)$ & \\
\hline & $>48 \mathrm{~h}$ & $158(49.4 \%)$ & $22(40.0 \%)$ & \\
\hline \multirow[t]{2}{*}{ Days to presentation } & & & & 0.285 \\
\hline & Median (Range) & $7(4,18)$ & $5(4,15)$ & \\
\hline \multirow[t]{4}{*}{ Mechanism } & & & & 0.146 \\
\hline & Scald, water & $117(36.0 \%)$ & $15(26.3 \%)$ & \\
\hline & Flame & $200(61.5 \%)$ & $42(73.7 \%)$ & \\
\hline & Other & $8(2.5 \%)$ & - & \\
\hline \multicolumn{5}{|l|}{ Nutritional characteristics } \\
\hline \multirow[t]{3}{*}{ Patient measured } & & & & 0.013 \\
\hline & Yes & 197 (59.7\%) & $24(42.1 \%)$ & \\
\hline & No & $133(40.3 \%)$ & $33(57.9 \%)$ & \\
\hline \multirow[t]{2}{*}{ Weight-for-age } & & 122 & 17 & 0.890 \\
\hline & Median (Range) & $-1.0(-1.77,0.20)$ & $-0.86(-1.81,-0.27)$ & \\
\hline \multirow[t]{2}{*}{ Height-for-age } & & 67 & 11 & 0.318 \\
\hline & Median (Range) & $-2.33(-4.0,-1.15)$ & $-3.57(-4.93,-1.36)$ & \\
\hline MUAC & & 51 & 5 & 0.615 \\
\hline & Median (Range) & $-0.58(-1.27,0.64)$ & $-0.94(-1.45,0.77)$ & \\
\hline Combined z score & & 141 & 22 & 0.447 \\
\hline & Median (Range) & $-1.65(-2.79,-0.6)$ & $-1.60(-4.66,-0.58)$ & \\
\hline BMI (pts > 20) & & 44 & 5 & 0.530 \\
\hline & Median (Range) & $20.2(18.1,23.4)$ & $24.2(18.5,25.5)$ & \\
\hline Interventions & & & & \\
\hline Traditional medicine & & & & 0.76 \\
\hline & Yes & 48 (15.1) & 7 (13.5\%) & \\
\hline & No & $270(84.6 \%)$ & $45(86.5 \%)$ & \\
\hline Antibiotics on admission & & & & 0.419 \\
\hline & Yes & 260 (79.8\%) & $42(75 \%)$ & \\
\hline & No & $66(20.3 \%)$ & $14(25 \%)$ & \\
\hline Time to OR & & & & 0.0001 \\
\hline & Median (Range) & $14(6,26)$ & $6(3,11)$ & \\
\hline Procedure & & & & $<0.001$ \\
\hline & Skin graft & $150(46.0 \%)$ & $8(14.68 \%)$ & \\
\hline & Debridement & $146(44.8 \%)$ & $27(50 \%)$ & \\
\hline & Escharotomy & $9(2.76 \%)$ & $12(22.2 \%)$ & \\
\hline & Amputation & $2(0.61 \%)$ & $2(3.7 \%)$ & \\
\hline & Contracture release & 7 (2.15\%) & $2(3.7 \%)$ & \\
\hline & Other & $12(3.68 \%)$ & $3(5.6 \%)$ & \\
\hline
\end{tabular}


Table 2 (continued)

\begin{tabular}{|c|c|c|c|c|}
\hline Variable & & Lived (330) & Died (57) & $\mathrm{p}$ Value \\
\hline \multirow[t]{2}{*}{ Length of stay } & & & & 0.0001 \\
\hline & Median (Range) & $44(26,70)$ & $19(12,35)$ & \\
\hline \multirow[t]{5}{*}{ Operative mortality for age categories } & & & & 0.073 \\
\hline & $<5$ & $155(85.2 \%)$ & $27(14.8 \%)$ & \\
\hline & $6-16$ & $70(90.1 \%)$ & $7(9.09 \%)$ & \\
\hline & $17-49$ & 90 (84.1\%) & $17(15.9 \%)$ & \\
\hline & $50+$ & $12(66.8 \%)$ & $6(33.3 \%)$ & \\
\hline
\end{tabular}

Table 3 - Unadjusted and adjusted odds ratios for the logistic regression model, risk of mortality.

\begin{tabular}{|c|c|c|c|}
\hline Variable & Unadjusted odds ratio (95\% CI) & Adjusted odds ratio $(95 \% \mathrm{CI})$ & p Value \\
\hline \multicolumn{4}{|l|}{ Overall model } \\
\hline Z score & $1.13(0.9,1.42)$ & $1.46(1.05,2.03)$ & 0.023 \\
\hline \multicolumn{4}{|l|}{ Procedure (vs skin graft) } \\
\hline -Debridement & $3.47(1.52,7.88)$ & $0.87(0.18,4.17$ & 0.863 \\
\hline -Escharotomy & $25(8.16,76.6)$ & $4.6(0.43,49.7)$ & 0.209 \\
\hline -Amputation & $18.8(2.33,150.8)$ & N/A & N/A \\
\hline -Contracture release & $5.4(0.95,30.1)$ & $0.90(0.04,23.4)$ & 0.952 \\
\hline -Other & $4.7(1.1,20.0)$ & $0.07(0.0,81.7)$ & 0.455 \\
\hline \%TBSA burned & $1.07(1.05,1.10)$ & $1.11(1.05,1.17)$ & 0.001 \\
\hline Time to operating room & $0.96(0.93,0.98)$ & $0.90(0.83,0.99)$ & 0.023 \\
\hline Age & $1.02(1.0,1.03)$ & $0.90(0.72,1.10)$ & 0.304 \\
\hline Flame burn & $1.32(0.76,2.32)$ & $0.83(0.21,3.25)$ & 0.788 \\
\hline
\end{tabular}

Operative mortality was associated with severe stunting. The median height-for-age $z$-scores were $-2.33(-4,-1.15)$ and $-3.57(-4.93,-1.36)$ for survivors and non- survivors, respectively, but this difference was not statistically significant. No significant differences were observed in the weight-for-age, MUAC-for-age, overall nutrition $\mathrm{z}$ score, or BMI. Primary outcome was unchanged based on comorbidities, HIV status, antibiotics administration, traditional medicine use, time to presentation, or mechanism of burn.

Based on significant covariates associated with mortality on bivariate analysis (Table 2), logistic regression modeling was performed, adjusting for \%TBSA, age, timing of operative intervention, and mechanism of burn (Table 3). Worsening

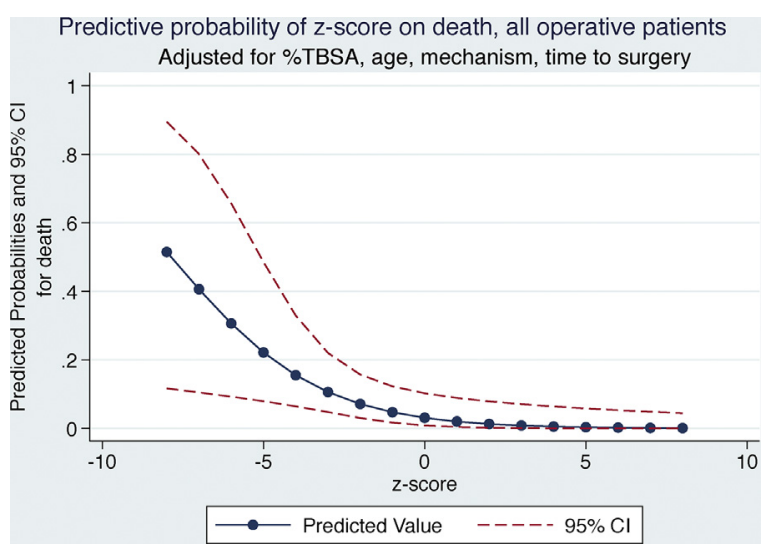

Fig. 1 - Predictive probability of z-score on death, all operative patients adjusted for \%TBSA, age, mechanism, time to surgery. pre-existing nutritional status based on z-scores was associated with an increase in the odds of mortality. Decreasing $z$ score by 1 resulted in increased odds of mortality by $46 \%$ (OR: 1.46, 95\% CI: 1.05, 2.03). Increasing \% TBSA burned (OR: 1.11, 95\% CI: $1.05,1.17)$ and increased time from presentation to operative intervention (OR: $0.90,95 \%$ CI: $0.83,0.99$ ) remained significant in the adjusted model. Fig. 1 shows the adjusted predicted probability of death for the overall surgical population.

\section{Discussion}

The current study shows that pre-existing malnutrition independently predicts increased burn injury mortality in burn patients undergoing surgical procedures. The compromised nutritional status of the patients likely explains the protective effect of delayed surgical intervention.

Advances in burn management in the developed world that improve burn survival center include: the early excision and grafting of burn wounds, as well as efforts to meet and exceed the nutritional and metabolic estimates [7,10,28,29]. However, the effect of early excision on mortality in LMICs is equivocal. We previously reported that early excision and grafting of burn wounds in the resource-poor population increases the odds of mortality [6]; however, Puri et al. in a study from India reported decreased mortality following early excision and grafting [28]. Their study compared ten patients who underwent excision and grafting within the first 5 days of hospital stay, to ten patients who underwent delayed operation at least three weeks after admission. The authors did not report the nutritional status of their patients. Our study suggests that 
early operative intervention increased surgical mortality in the presence of pre-existing malnutrition.

Burn injury survival in SSA continues to lag behind the developed world, despite favorable burn injury characteristics that should portend increased survival, such as young age [25], a low average \%TBSA of $<30 \%$, and the low incidence of inhalation injury. The overall reported mortality ranges from $10 \%$ to $26.8 \%$ [4]. We identified two previous studies from the region [16,29], which report the nutritional status of burn patients. A recent study of 211 pediatric burn patients in Tanzania [29] reported a $7.6 \%$ prevalence of underweight (defined using weight-for-age z-scores) and showed no association between underweight and mortality. The median \%TBSA in this report was only 8\% (IQR: 5-13.4\%), and operative intervention was infrequent. Similarly, a study from rural the Eastern Cape of South Africa looked at 67 burn patients and did not find an association between malnutrition and mortality [16].

In 2012, 42.6\% of Malawi's population lived in the $\mathrm{KCH}$ catchment area of Central Malawi [30]. Therefore, the very high overall level of under nutrition in our pediatric patient population likely reflects the overall compromised nutritional status of children in the entire country. The median utilized z-score in our patient cohort falls more than -1 SD below the mean and the high prevalence of stunting in our patients also likely reflects the chronic food insecurity in the country. The nutritional situation of our adult patients is difficult to determine using the available indicators of adult malnutrition, which are based on expert opinion and have not been validated in LMICs. However, based on an analysis of data from 56 countries in Africa, Asia and Latin America [31], information on under-nutrition prevalence in LMIC children can be considered a surrogate for the overall nutritional status and food security conditions in a country; therefore it is likely that in Malawi, a high prevalence of malnutrition in children reflects a similarly high percentage of adult malnutrition.

The majority of adults in our study did not have height measurements for BMI calculation; however, BMI did not affect the primary outcome. The contribution of under nutrition to increased operative mortality in adult burn patients, particularly in adults aged over 50 and those with a relatively small \% TBSA, will need further study. Furthermore, due to the limited availability of diagnostic studies and access to basic health care, the true prevalence of concomitant comorbidities, such as a HIV, and their effect on burn mortality remains unknown.

Our study is limited by its retrospective methodology and by the relatively small number of adult patients with available BMI calculations. The depth of the burn was also not assessed nor was there an injury severity score calculated or available. Moreover, using one data point for anthropomorphic measurements can introduce an element of imprecision. The patients who died were weighed or measured less frequently than did those who lived. This may be due to the tendency of the support staff not to manipulate patients with larger burns in order to weigh them. Additionally, pain may have been a factor, as patients must stand up to be weighed, and analgesic medications are not always available.

Due to the resource limitations of our environment, the clinical and laboratory documentation of sepsis or organ failure is not currently possible; however, as the majority of patient measurements took place early during their hospital stay, burn-related infection and organ failure likely did not significantly confound the patients' nutritional status. Our study is strengthened by the fact that all patients are cared for in a dedicated burn unit, minimizing any confounding due to the standard of care. The resource limitations of Malawian healthcare exist in comparison to resource-rich countries, and not within Malawian public hospitals, with all patients receiving standard treatment. Furthermore, there was no nutritional intervention being evaluated in our study, and therefore all patients received the same meals during their hospital stay. The fact that patient families may bring additional food from home could have been a confounder in our study. The study population is large, and data collection methods standardized across the study period. Furthermore, the predominance of pediatric patients mirrors the epidemiology of burns in SSA, thereby making our conclusions applicable to this patient population.

\section{Conclusion}

We have demonstrated that pre-existing malnutrition is an independent risk factor for increased post-operative mortality following burn injury intervention in a resource-poor setting. Aggressive, early nutritional intervention should be standard practice for all patients in SSA burn units, prior to, during, and after operative intervention. Burn outcomes SSA will continue to lag behind that of developed countries in the absence of a robust nutrition support program in burn units. In the cohort of burn patients with malnutrition needing operative intervention, it is advisable to delay operative intervention to prevent unnecessary mortality.

\section{Conflict of interest statement}

Pre-existing malnutrition increases operative mortality in a sub-Saharan Africa burn unit

The authors whose names are listed immediately below certify that they have NO affiliations with or involvement in any organization or entity with any financial interest (such as honoraria; educational grants; participation in speakers' bureaus; membership, employment, consultancies, stock ownership, or other equity interest; and expert testimony or patent-licensing arrangements), or non-financial interest (such as personal or professional relationships, affiliations, knowledge or beliefs) in the subject matter or materials discussed in this manuscript.

R E F E R E N C E S

[1] WHO. Estimates for 2000-2015 [Internet]. WHO. Available from: http://www.who.int/healthinfo/ global_burden_disease/estimates/en/ [Accessed 22 May 2017].

[2] Fourjuh S. Burns in low- and middle-income countries: a review of literature on descriptive epidemiology, risk factors, treatment, and prevention. Burns 2006;32:529-37. 
[3] Albertyn R, Bickler SW, Rode H. Paediatric burn injuries in Sub Saharan Africa-an overview. Burns 2006;32(August (5)): 605-12.

4 Nthumba P. Burns in sub-Saharan Africa: a review. Burns 2016;42(March (2)):258-66.

[5] Tyson A, Boschini L, Kiser M, Samuel J, Mjuweni S, Cairns B, et al. Survival after burn injury in a sub-Saharan burn unit: challenges and opportunities. Burns 2013;39(December (8)):1619-25.

[6] Gallaher JR, Mjuweni S, Shah M, Cairns BA, Charles AG. Timing of early excision and grafting following burn in sub-Saharan Africa. Burns 2015;41(September (6)):1353-9.

[7] Jeschke MG, Williams F, Gauglitz G, Herndon DN. Burns. In: Townsend, editor. et al. Sabiston textbook of surgery. 19th ed. Philadelphia, PA: Elsevier-Saunders; 2012. p. 521-47.

[8] Burke JF, Bondoc CC, Quinby WC. Primary burn excision and immediate grafting: a method shortening illness. J Trauma 1974;14(May (5)):389-95.

[9] Pietsch JB, Netscher DT, Nagaraj HS, Groff DB. Early excision of major burns in children: effect on morbidity and mortality. J Pediatr Surg 1985;20(December (6)):754-7.

[10] Tompkins RG, Remensnyder JP, Burke JF, Tompkins DM, Hilton JF, Schoenfeld DA, et al. Significant reductions in mortality for children with burn injuries through the use of prompt eschar excision. Ann Surg 1988;208(November (5)): 577-85.

[11] Ong YS, Samuel M, Song C. Meta-analysis of early excision of burns. Burns 2006;32(March (2)):145-50.

[12] Hart DW, Wolf SE, Mlcak R, Chinkes DL, Ramzy PI, Obeng MK, et al. Persistence of muscle catabolism after severe burn. Surgery 2000;128(August (2)):312-9.

[13] Reiss E, Pearson E, Artz CP. The metabolic response to burns. J Clin Invest 1956;35(January (1)):62-77.

[14] Fagan SP, Bilodeau M-L, Goverman J. Burn intensive care. Surg Clin North Am 2014;94(August (5)):765-79.

[15] Newsome TW, Mason AD, Pruitt BA. Weight loss following thermal injury. Ann Surg 1973;178(August (2)):215-7.

[16] Vijfhuize S, Verburg M, Marino L, van Dijk M, Rode H. An evaluation of nutritional practice in a paediatric burns unit. South Afr Med J 2010;100(June (6)):383-6.

[17] Pelletier DL, Frongillo EA, Schroeder DG, HabichtJP. The effects of malnutrition on child mortality in developing countries. Bull World Health Organ 1995;73(4):443-8.

[18] Kingu HJ, Longo-Mbenza B, Dhaffala A, Mazwai EL. Survival function and protein malnutrition in burns patients at a rural hospital in Africa. World J Surg 2011;35(June (7)): 1546-52.
[19] WHO. Moderate malnutrition [Internet]. WHO. Available from http://www.who.int/nutrition/topics/ moderate_malnutrition/en/ [Accessed 22 May 2017].

[20] White JV, Guenter P, Jensen G, Malone A, Schofield M, Academy of Nutrition and Dietetics Malnutrition Work Group, et al. Consensus statement of the Academy of Nutrition and Dietetics/American Society for Parenteral and Enteral Nutrition: characteristics recommended for the identification and documentation of adult malnutrition (undernutrition). J Acad Nutr Diet 2012;112(May (5)): 730-8.

[21] Becker PJ, Nieman Carney L, Corkins MR, Monczka J, Smith E, Smith SE, et al. Consensus statement of the Academy of Nutrition and Dietetics/American Society for Parenteral and Enteral Nutrition: indicators recommended for the identification and documentation of pediatric malnutrition (undernutrition). J Acad Nutr Diet 2014;114(December (12)):1988-2000.

[22] Bhaskaran K, Douglas I, Forbes H, dos-Santos-Silva I, Leon DA, Smeeth L. Body-mass index and risk of 22 specific cancers: a population-based cohort study of 5.24 million UK adults. Lancet 2014;384(August (9945)):755-65.

[23] Nutrition Landscape Information System Nutrition Landscape Information System (NLIS) Country Profile [Internet]. http:// apps.who.int/nutrition/landscape/report.aspx? iso=MWI\&rid=1620\&goButton=Go [Accessed 22 May 2017].

[24] Malawi Data [Internet]. Available from: http://data.worldbank. org/country/Malawi [Accessed 21 June 2017].

[25] Health expenditure per capita (current US\$) Data. http://data. worldbank.org/indicator/SH.XPD.PCAP?year_high_desc=false [Accessed 25 July 2017].

[26] WHO. WHO Anthro (version 3.2.2, January 2011) and macros. WHO. Available from: http://www.who.int/childgrowth/ software/en/ [Accessed 22 May 2017].

[27] PediTools Home [Internet]. Available from: http://www. peditools.org/ [Accessed 22 May 2017].

[28] Puri V, Khare NA, Chandramouli MV, Shende N, Bharadwaj S. Comparative analysis of early excision and grafting vs delayed grafting in burn patients in a developing country. J Burn Care Res 2016;37(October (5)):278-82.

[29] Chelidze KI, Lim CC, Peck RN, Giiti G, Leahy N, Rabbitts A, et al. Predictors of mortality among pediatric burn patients in East Africa. J Burn Care Res 2016;37(April (2)):e154-60.

[30] Population Reference Bureau. Available from: http://www.prb. org/ [Accessed 25 July 2017].

[31] Nubé M. Relationships between undernutrition prevalence among children and adult women at national and subnational level. Eur J Clin Nutr 2005;59(October (10)):1112-20. 